\title{
Calculated Neutron and Gamma-Ray Spectra Across the Prismatic Very High Temperature Reactor Core
}

\section{$13^{\text {th }}$ International Symposium on Reactor Dosimetry}

\section{James W. Sterbentz}

May 2008

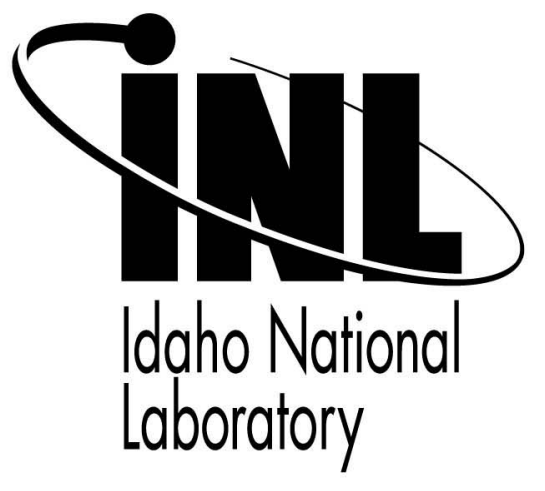

This is a preprint of a paper intended for publication in a journal or proceedings. Since changes may be made before publication, this preprint should not be cited or reproduced without permission of the author. This document was prepared as an account of work sponsored by an agency of the United States Government. Neither the United States Government nor any agency thereof, or any of their employees, makes any warranty, expressed or implied, or assumes any legal liability or responsibility for any third party's use, or the results of such use, of any information, apparatus, product or process disclosed in this report, or represents that its use by such third party would not infringe privately owned rights. The views expressed in this paper are not necessarily those of the United States Government or the sponsoring agency. 


\title{
CALCULATED NEUTRON AND GAMMA-RAY SPECTRA ACROSS THE PRISMATIC VERY HIGH TEMPERATURE REACTOR CORE
}

\author{
JAMES W. STERBENTZ \\ Idaho National Laboratory \\ P.O. Box 1625, Idaho Falls, Idaho, United States 83415-3870 \\ James.Sterbentz@inl.gov
}

\begin{abstract}
Neutron and gamma-ray flux spectra are calculated using the MCNP5 computer code and a one-sixth core model of a prismatic Very High Temperature Reactor based on the General Atomics Gas Turbine-Modular Helium Reactor. Spectra are calculated in the five inner reflector graphite block rings, three annular active core fuel rings, three outer graphite reflector block rings, and the core barrel. The neutron spectra are block and fuel pin averages and are calculated as a function of temperature and burnup. Also provided are the total, fast, and thermal radial profile fluxes and core barrel dpa rates.
\end{abstract}

\section{Introduction}

The Generation IV Very High Temperature Reactor (VHTR) concept is under consideration for deployment in the United States as the Next Generation Nuclear Plant (NGNP). The U. S. Department of Energy continues to develop technology and define possible missions for the proposed NGNP reactor, but has not yet decided if it will be a VHTR with a prismatic-block or pebble-bed core. However, the current direction seems to favor a prismatic-block core for the U.S. VHTR, since the South Africans are pressing ahead with the pebble-bed VHTR core.

The prismatic VHTR reactor is a thermal spectrum reactor characterized by a relatively low core power density $\left(6.6 \mathrm{~W} / \mathrm{cm}^{3}\right)$, an annular three-ring active core composed of prismatic fuel blocks, and an inner and outer graphite radial reflector. The low power density, TRISOcoated particle fuel, large graphite mass and strong negative Doppler fuel coefficient of reactivity ensures that this reactor core concept will adhere to the underlying Generation IV goal of inherent safety under all accident or transient conditions. In addition, the high outlet helium gas temperature $\left(900-950{ }^{\circ} \mathrm{C}\right)$ allows for efficient electricity generation $(48 \%$ Brayton cycle), hot gas heat, and hydrogen production. The neutronic spectral analysis and computer models herein are based solely on the helium-cooled VHTR at $600 \mathrm{MW}_{\text {th }}$ and 
specifically on the General Atomics Gas Turbine-Modular Helium Reactor (GT-MHR) concept ${ }^{1}$.

\section{Core Description}

The GT-MHR core contains hexagonal fuel and solid graphite reflector blocks. The active annular core is composed of 102 fuel columns in rings 6, 7, and 8 (Figure 1-blue hexagons). The inner graphite reflector blocks (rings 1-5) and the outer graphite reflector blocks (rings 9-11). Rings 9 and 10 are the replaceable reflector blocks and ring 11 is the permanent side reflector block ring that could contain a thermal neutron poison to reduce the cumulative lifetime thermal neutron damage to the core barrel (SS304L or Alloy 800H). Each fuel column is a vertical stack of ten fuel blocks for a total of 1,020 fuel blocks in the core.

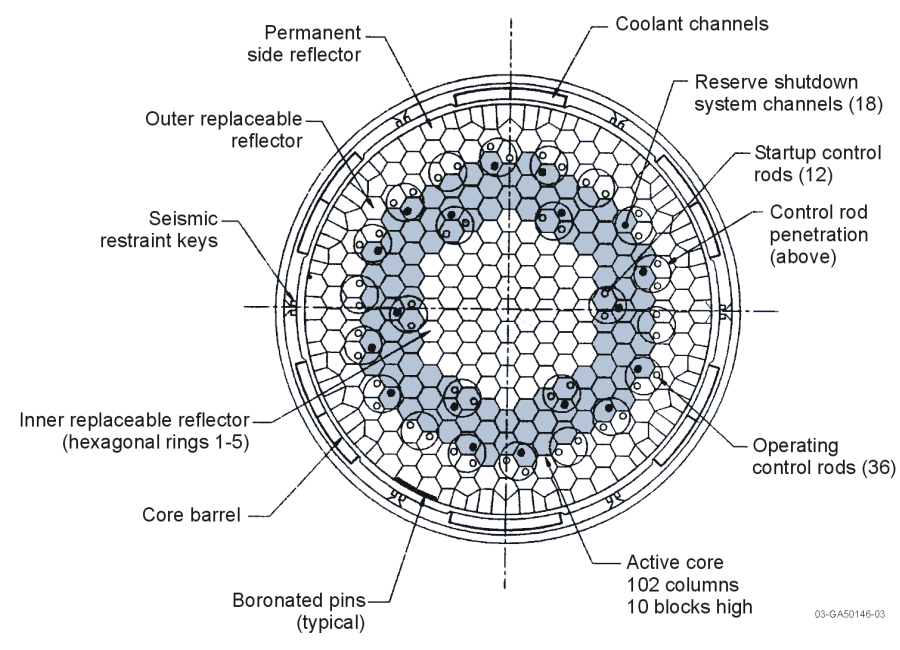

Figure 1. The General Atomics GT-MHR reactor core.

Although the GT-MHR concept incorporates three different types of fuel blocks in the core: standard, reserve shutdown, and control rod, we assume for simplicity that all fuel blocks are standard fuel blocks in our models. There are 210 drilled fuel channels in each fuel block and are filled with TRISO fuel compacts. Each cylindrical fuel compact contains TRISO-coated fuel particles bound in a graphite matrix; diameter of a compact is $1.245 \mathrm{~cm}$ and $4.93 \mathrm{~cm}$ long. A typical fuel rod channel in a prismatic-block would contain 15 vertically-stacked compacts for a total fuel rod length of approximately $74 \mathrm{~cm}$.

The initial VHTR core model considered in the analysis here is assumed to have the annular core loaded with identical standard fuel blocks with zero burnup or 0 EFPD (Effective Full 
Power Days) and the following characteristics: $10.36 \mathrm{wt} \%$ enrichment, $350 \mu \mathrm{m}$ UCO TRISO particle kernel diameter, compact TRISO particle packing fraction of $28.9 \%, 554 \mathrm{~g} / \mathrm{block} \mathrm{U}$ 235 fuel block loading, $1.8796 \mathrm{~cm}$ fuel rod pitch, and a $36 \mathrm{~cm}$ flat-to-flat block dimension.

In the computer model, the fuel rod material composition is assumed to be a homogenized mixture of the TRISO fuel particles and compact matrix binder material. The U-235 block loading is enough to meet the 18 -month power cycle length goal and a total core power of $600 \mathrm{MW}_{\text {th }}$.

The depleted-initial core model has characteristics similar to the initial core, except the core has achieved 604 EFPD burnup and the fuel rod compositions now reflect this burnup. Since there are 210 fuel rods per block and three annular fuel rings, this core model contains 630 unique fuel compositions with different burnups. The block fuel compositions are assumed to be the same for all blocks in a given fuel ring. Included in the burnup fuel compositions are six uranium and plutonium actinides and 16 fission products with the largest negative reactivity contributions, plus the TRISO particle matrix material isotopes.

The depleted-reload core model was burned for a total of 480 EFPD. The beginning-ofcycle (BOC) reload core started with initial core fuel blocks (10.36 wt\% enrichment) with 523 EFPD burnup in Rings 6 and 8, and fresh fuel blocks (14 wt\% enrichment or $776 \mathrm{~g} / \mathrm{block}$ U-235 loading) in Ring 7. The BOC reload core was then burned for 480 EFPD and spectra calculated for the core at EOC in order to maximize burnup spectral differences.

\section{Computer Codes and Models}

The three computer codes, $\mathrm{MCNP}^{2}$, ORIGEN2.2 $2^{3}$, and MOCUP ${ }^{4}$ were used to perform the depletion analysis of the three cores (initial, depleted-initial, and depleted-reload), estimate core $\mathrm{k}$ effectives, and calculate the neutron and gamma-ray spectra include $\mathrm{MCNP}^{2}$, ORIGEN2.2 $2^{3}$, and MOCUP ${ }^{4}$. These codes and the calculational methodologies used to link the codes for the depletion analysis are described in detail in Reference 5.

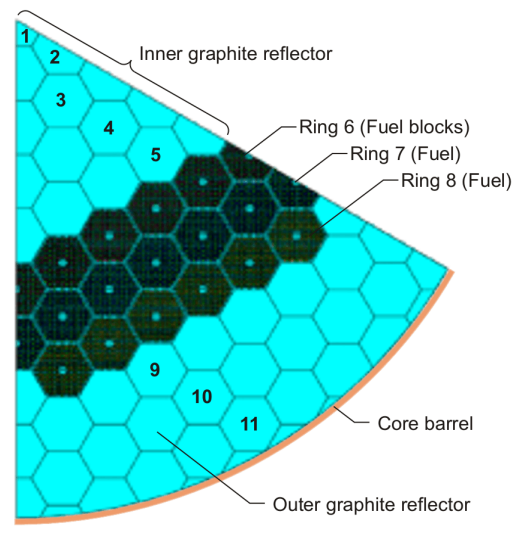

Figure 2. MCNP one-sixth core model.

An explicit, three-dimensional, MCNP5 one-sixth core model was developed for the neutronic and depletion analyses (Figure 2). Reflective surface boundary conditions are applied to the two azimuthal surfaces (wedge sides) and the top and bottom surfaces to create 
an infinite axial extent and azimuthally symmetric core. The model includes solid hexagonal graphite blocks with handling/tooling holes for the inner and outer reflector regions.

The MCNP core models do not include the localized effects of inserted control rods, burnable poison rods, or core fuel loading optimizations.

\section{Calculated Neutron and Gamma-ray Spectra}

The calculated neutron and gamma-ray spectra are presented in this section for three cores with different burnups: (1) initial core (0 EFPD), (2) depleted-initial core (604 EFPD), and (3) depleted-reload core (480 EFPD). The neutron and gamma-ray spectra are normalized to a $600 \mathrm{MW}_{\text {th }}$ total core power. In the figures, the neutron spectra or lethargy flux are plotted in units of "neutrons $/ \mathrm{cm}^{2} / \mathrm{sec} / \mathrm{u}$," where the "u" is per "unit of lethargy." The gamma-ray spectra are plotted as gamma group fluxes in units of "gammas $/ \mathrm{cm}^{2} / \mathrm{sec}$." The gamma spectra include prompt fission gamma-rays and radiative capture gammas, but not fission product gammas. Both neutron and gamma spectra were calculated using a 95-group $(0.25 \mathrm{u})$ energy structure over the energy range of $0-14 \mathrm{MeV}$ for neutrons and $0.001-14 \mathrm{MeV}$ for gammas. The MCNP code does not transport photon radiation below $1 \mathrm{keV}$. The MCNP core models were run with $>800$ million particles in order to achieve statistical relative errors $<4 \%$ even in the fast neutron energy groups at the core barrel. The spectral plots include the block-average spectra in the graphite blocks in Rings 1-5 (inner reflector), fuel rod-average in the annular core blocks in Rings 6, 7, and 8, and graphite blocks in Rings 9-11 (outer reflector). In addition, a core barrel average spectrum is included along with the graphite at the interface between the inner graphite reflector (ring 5) and the inner radial surface of the annular core (ring 6 fuel block).

\subsection{Initial Core Neutron Spectra}

Neutron energy flux spectra are given for the initial core (0 EFPD) with the fuel at a uniform temperature of $1100{ }^{\circ} \mathrm{C}$ and the graphite at $927{ }^{\circ} \mathrm{C}$. These temperature conditions would be typical at full-power conditions near or just below the core midplane (Figures 3-5). 


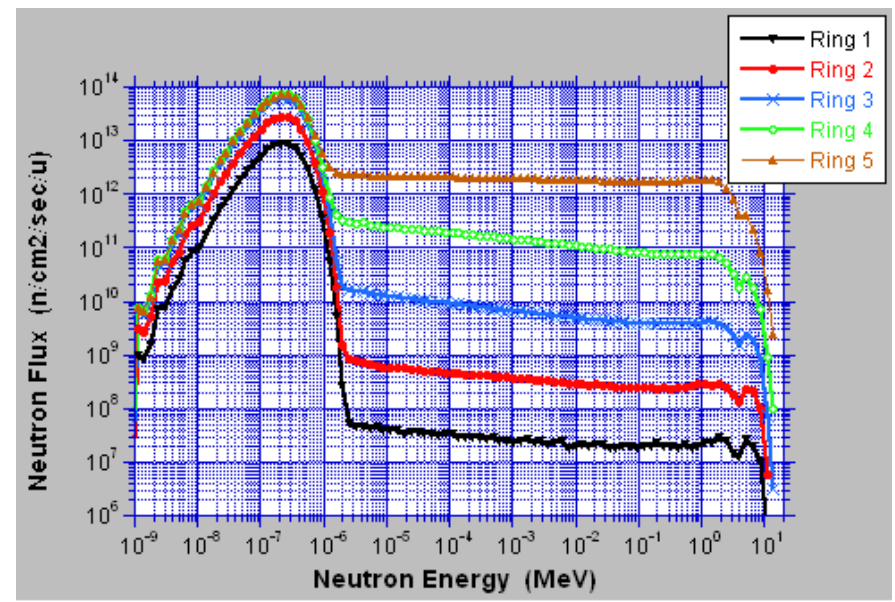

Figure 3. Inner graphite reflector neutron spectra at $927^{\circ} \mathrm{C}$.

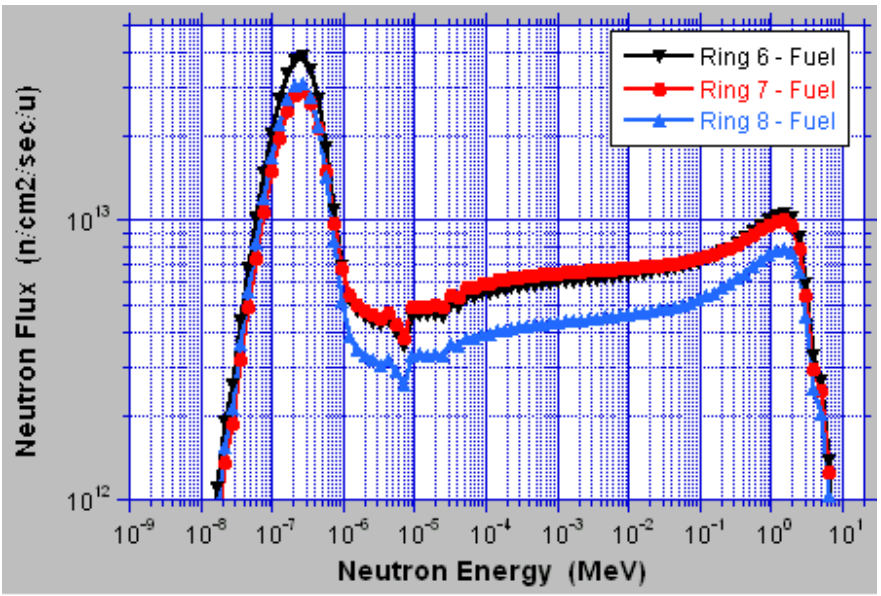

Figure 4. Fuel spectra for $1100{ }^{\circ} \mathrm{C}$ fuel and $927^{\circ} \mathrm{C}$ graphite. 


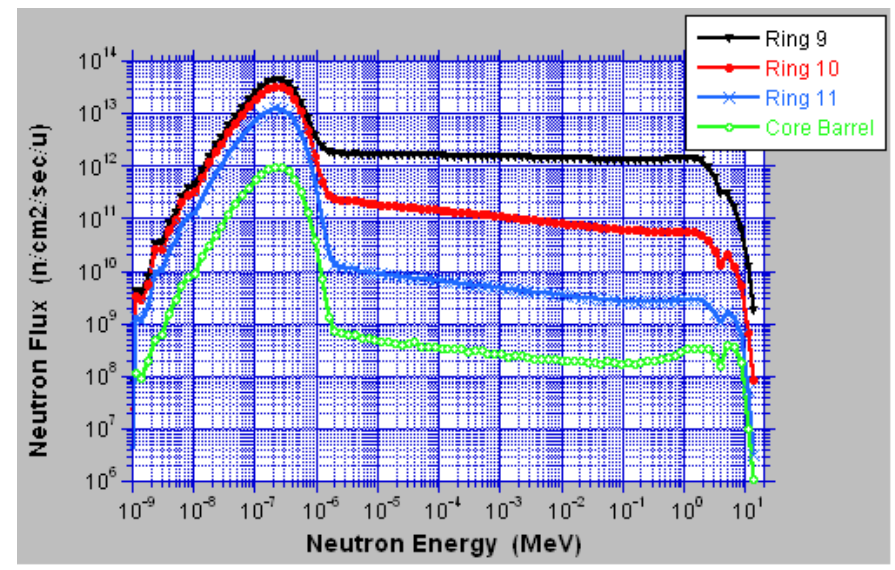

Figure 5. Outer graphite reflector block spectra at $927^{\circ} \mathrm{C}$.

In order to more clearly demonstrate the effects of fuel and graphite temperature on the neutron spectra, Figures 6 and 7 provide a spectra overlay of the inner reflector blocks (rings 1 and 5) and a fuel block (ring 6), respectively, at two different temperatures.

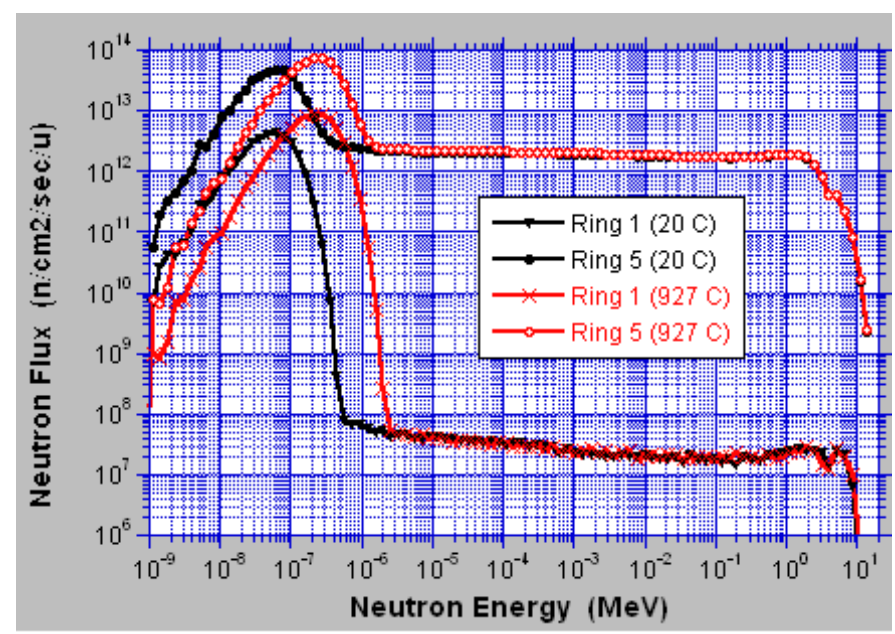

Figure 6. Inner reflector graphite spectra at 20 and $927^{\circ} \mathrm{C}$. 


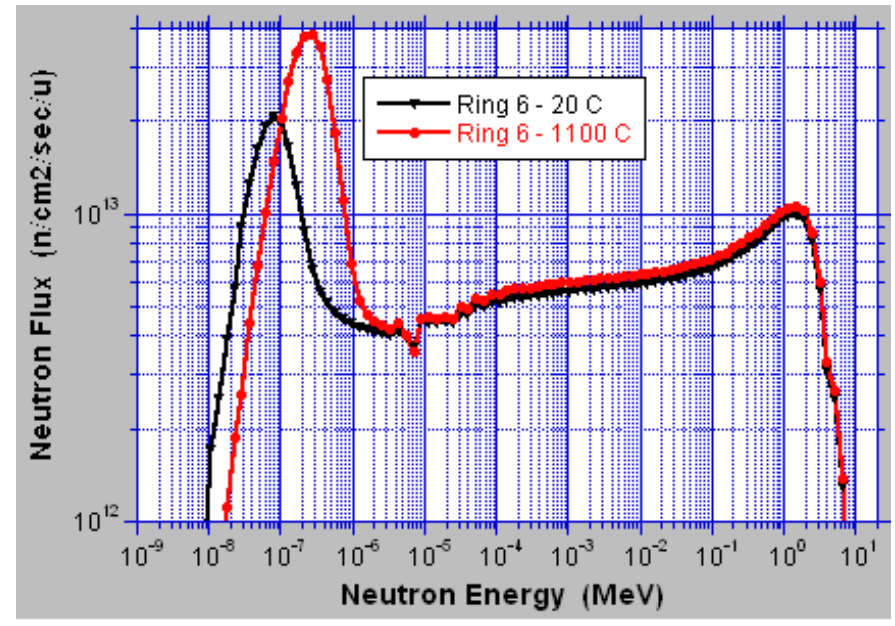

Figure 7. Fuel rod spectra at $20^{\circ} \mathrm{C}$ and $1100^{\circ} \mathrm{C}$ fuel.

\subsection{Initial Core Gamma-ray Spectra}

The calculated gamma-ray flux spectra for the initial core at $1100{ }^{\circ} \mathrm{C}$ fuel and $927^{\circ} \mathrm{C}$ graphite temperature conditions are shown in Figures 8 and 9. Figure 8 shows the gamma spectra in the inner graphite reflector blocks and Figure 14 in the fuel rods (rings 6-8) and at the inner reflector-core interface. It can be noted that the outer reflector blocks exhibit similar gamma spectra as the inner reflector blocks.

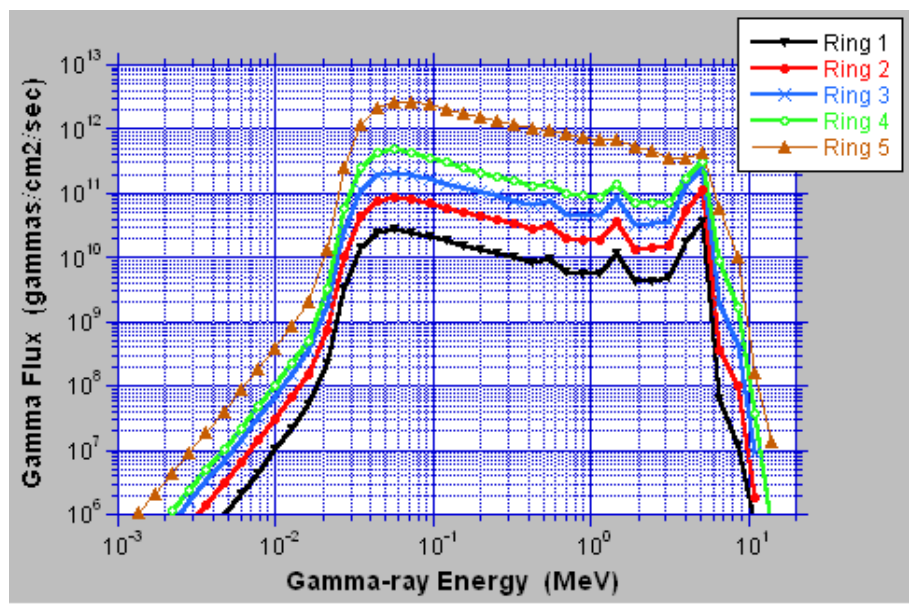

Figure 8. Inner reflector block gamma spectra at $927^{\circ} \mathrm{C}$. 


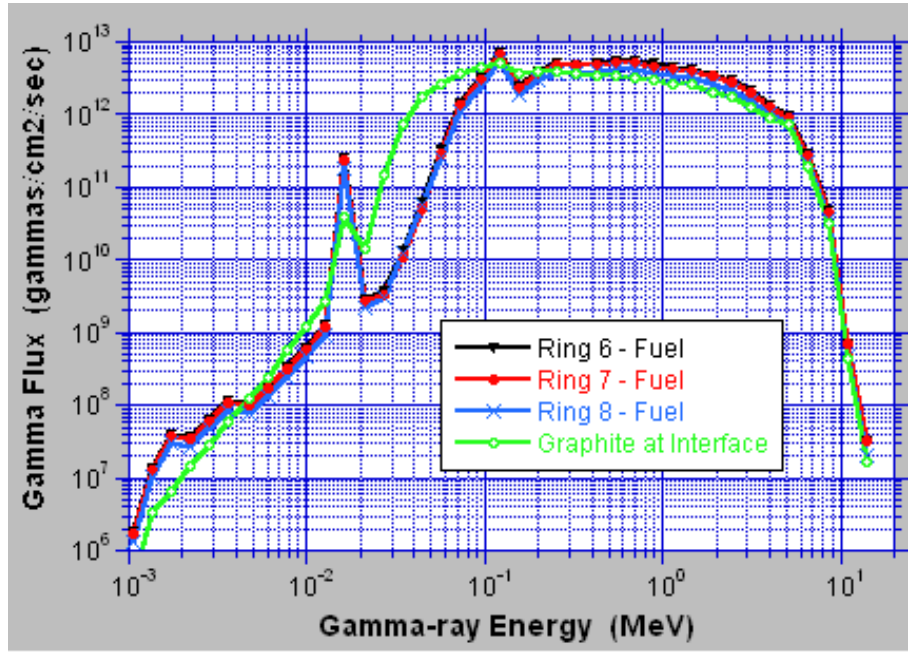

Figure 9. Fuel rod gamma spectra at $1100^{\circ} \mathrm{C}$.

\subsection{Depleted-Initial and Depleted-Reload Cores}

Neutron spectrum comparisons are made between the initial (0 EFPD), depleted-initial (604 EFPD), and the depleted-reload (480 EFPD) cores at the $1100{ }^{\circ} \mathrm{C}$ fuel and $927^{\circ} \mathrm{C}$ graphite temperature conditions. Figure 10 shows the difference in the average fuel rod neutron spectra for ring 7 fuel blocks only. An interesting difference between the three cores is the decrease in magnitude of the thermal peak with core burnup. In addition, the fast and epithermal fluxes tend to increase in magnitude for the depleted-initial and depleted-reload cores relative to the initial core. This may be due in part to the buildup of higher order actinides, in particular Pu-239, and a resulting increase of higher energy fission neutrons and a slight increase in the proportion of fast fission with burnup. Also, there appears to be no spectral energy shift in either the thermal or fast peaks for the three cores.

Although no spectral plot is provided, a comparison of the neutron spectra in the inner and outer graphite reflector blocks and core barrel for the three cores virtually over laid one another, suggesting the neutron spectra are independent of core burnup. 


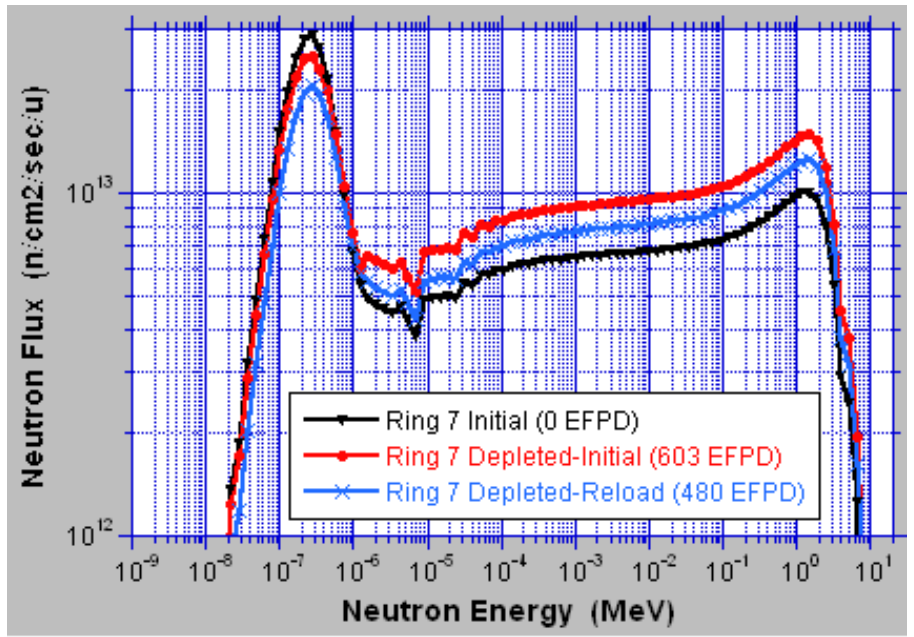

Figure 10. Fuel rod neutron spectra for the three cores.

\subsection{Neutron Flux Characteristics}

Table 1 gives the thermal, fast, and total neutron flux by core ring for the initial core. These fluxes are normalized to a core total power of $600 \mathrm{MW}_{\text {th }}$ and would be typical of flux magnitudes near core midplane or maximum core fluxes. The thermal flux is for neutrons of energy $<2.023 \mathrm{eV}$ and the fast flux is for neutrons of energy $>0.18 \mathrm{MeV}$. 
Table 1. Thermal, fast, and total block average neutron flux $(\mathrm{n} / \mathrm{cm} 2 / \mathrm{sec})$.

\begin{tabular}{|c|c|c|c|}
\hline Ring No. & Thermal & Fast & Total \\
\hline 1 & $1.665+13$ & $7.776+7$ & $1.665+13$ \\
\hline 2 & $5.258+13$ & $9.000+8$ & $5.258+13$ \\
\hline 3 & $1.159+14$ & $1.231+10$ & $1.160+14$ \\
\hline 4 & $1.370+14$ & $2.165+11$ & $1.390+14$ \\
\hline 5 & $1.410+14$ & $5.120+12$ & $1.69+14$ \\
\hline Interface & $1.058+14$ & $1.897+13$ & $1.769+14$ \\
\hline 6 & $7.817+13$ & $2.782+13$ & $1.716+14$ \\
\hline 7 & $6.052+13$ & $2.654+13$ & $1.568+14$ \\
\hline 8 & $6.268+13$ & $2.081+13$ & $1.309+14$ \\
\hline 9 & $8.378+13$ & $3.772+12$ & $1.045+14$ \\
\hline 10 & $5.962+13$ & $1.612+11$ & $6.111+13$ \\
\hline 11 & $2.315+13$ & $8.636+9$ & $2.323+13$ \\
\hline Barrel & $1.766+12$ & $1.020+9$ & $1.770+12$ \\
\hline
\end{tabular}

\subsection{Fast Neutron Flux Characteristics}

Table 2 gives the percentage of fast neutron flux above $0.1,0.18$, and $1.0 \mathrm{MeV}$ relative to the total flux for the initial core at the $1100{ }^{\circ} \mathrm{C}$ fuel and $927^{\circ} \mathrm{C}$ graphite temperature conditions. The calculated fluxes are based on block-averages.

Table 2. Fast flux percentage (\%) for the initial core.

\begin{tabular}{|c|c|c|c|}
\hline Ring No. & $>0.1 \mathrm{MeV}$ & $>0.18 \mathrm{MeV}$ & $>1.0 \mathrm{MeV}$ \\
\hline 1 & $5.383-4$ & $4.669-4$ & $2.596-4$ \\
\hline 2 & $1.976-3$ & $1.712-3$ & $8.778-4$ \\
\hline 3 & $1.253-2$ & $1.061-2$ & $4.914-3$ \\
\hline 4 & 0.1890 & 0.1557 & 0.06109 \\
\hline 5 & 3.630 & 3.028 & 1.175 \\
\hline Interface & 12.52 & 10.73 & 4.602 \\
\hline 6 & 18.77 & 16.21 & 7.229 \\
\hline 7 & 19.75 & 16.93 & 7.334 \\
\hline 8 & 18.35 & 15.89 & 7.140 \\
\hline 9 & 4.333 & 3.611 & 1.398 \\
\hline 10 & 0.3200 & 0.2635 & 0.1029 \\
\hline 11 & 0.04389 & 0.03718 & 0.01724 \\
\hline Barrel & 0.06331 & 0.05762 & 0.03526 \\
\hline
\end{tabular}


Figure 11 shows the magnitude of the block-average fast flux above $>0.18 \mathrm{MeV}$ across the initial, depleted-initial, and depleted-reload cores at the $1100{ }^{\circ} \mathrm{C}$ fuel and $927^{\circ} \mathrm{C}$ graphite temperature conditions. It appears that there is virtually no radial variation in the fast flux gradients as a function of burnup, particularly in the inner and outer reflector regions.

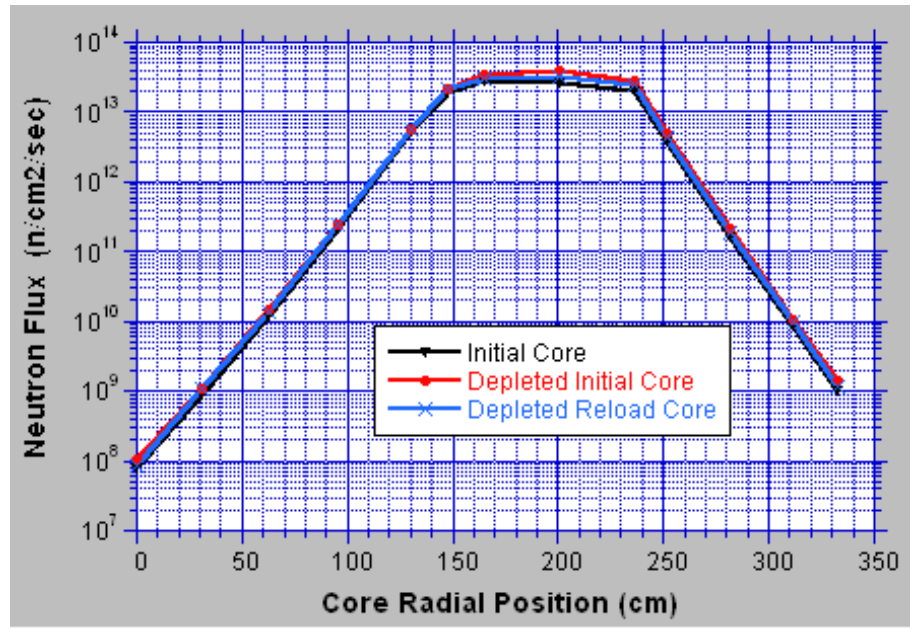

Figure 11. Core radial fast neutron flux $(>0.18 \mathrm{MeV})$ as a function of core burnup.

\subsection{Core Barrel DPA Rates}

The core barrel thermal, epi-thermal, and fast neutron $\mathrm{dpa}^{6}$ rates are calculated for the initial core (no thermal neutron poison in the permanent side reflector). Since the core barrel material has not yet been selected, dpa rates are estimated for iron ( $\mathrm{Fe})$, nickel $(\mathrm{Ni})$, chromium (Cr), stainless steel 304L, Alloy $800 \mathrm{H}$, and the ferritic steel alloy 9Cr-1Mo (Table 4).

Table 4. Dpa rates (dpa/day) for the core barrel.

\begin{tabular}{|c|c|c|c|c|}
\hline Material & Thermal $(<2.023 \mathrm{eV})$ & Epi-thermal & Fast $(>0.18 \mathrm{MeV})$ & Total \\
\hline $\mathrm{Fe}$ & $6.646 \mathrm{E}-7$ & $4.279 \mathrm{E}-9$ & $7.818 \mathrm{E}-8$ & $7.471 \mathrm{E}-7$ \\
\hline $\mathrm{Ni}$ & $1.474 \mathrm{E}-6$ & $7.213 \mathrm{E}-9$ & $8.165 \mathrm{E}-8$ & $1.563 \mathrm{E}-6$ \\
\hline $\mathrm{Cr}$ & $1.129 \mathrm{E}-6$ & $5.016 \mathrm{E}-9$ & $8.583 \mathrm{E}-8$ & $1.220 \mathrm{E}-6$ \\
\hline $\mathrm{SS} 304 \mathrm{~L}$ & $8.286 \mathrm{E}-7$ & $4.696 \mathrm{E}-9$ & $7.995 \mathrm{E}-8$ & $9.132 \mathrm{E}-7$ \\
\hline $800 \mathrm{H}$ & $1.022 \mathrm{E}-6$ & $5.366 \mathrm{E}-9$ & $8.052 \mathrm{E}-8$ & $1.108 \mathrm{E}-6$ \\
\hline 9Cr-1Mo & $7.145 \mathrm{E}-7$ & $4.375 \mathrm{E}-9$ & $7.891 \mathrm{E}-8$ & $7.978 \mathrm{E}-7$ \\
\hline
\end{tabular}




\section{Conclusions}

Calculated block-average neutron and gamma-ray spectra are presented as a function of radial position across the core of a $600 \mathrm{MW}_{\text {th }}$ helium-cooled prismatic block VHTR. Plots of the neutron spectra reveal several interesting characteristics: (1) decrease in magnitude and strong thermalization in the graphite reflectors with increasing radial distance from the annular core, (2) strong temperature-dependence of the thermal neutron spectra everywhere in the core with the bulk graphite temperature controlling both the thermal neutron peak energy and magnitude, (3) fuel rod spectra vary between the annular rings and have both a temperature and burnup dependence, (4) graphite reflector spectra are very weakly dependent on core burnup and fuel block uranium loading, (5) the core barrel spectra are temperaturedependent, but independent of core burnup, and (6) the core barrel dpa damage is due primarily to thermal neutrons. Comparison of the gamma-ray spectra (prompt fission and radiative capture) between the fuel rods and graphite reflector blocks show characteristic differences in energy and magnitude, but neither was dependent on temperature or burnup.

\section{References}

1. "Gas Turbine-Modular Helium Reactor (GT-MHR) Conceptual Design Description Report," Revision 1, Report 910720, GA Project No. 7658, General Atomics, San Diego, CA (1996).

2. “MCNP-A General Monte Carlo N-Particle Transport Code, Version 5," X-5 Monte Carlo Team, Los Alamos National Laboratory, New Mexico, April 2003.

3. S. B. Ludwig and A.G. Croft, "ORIGEN2.2-Isotope Generation and Depletion Code - Matrix Exponential Method," Oak Ridge National Laboratory, Oak Ridge, Tennessee, March 2002

4. R.S. Babcock, et. al., "The MOCUP Interface: A Coupled Monte Carlo/Depletion System," Idaho National Engineering Laboratory, Topical Meeting on Advances in Reactor Physics, Vol. III, Knoxville, Tennessee, April 1-5, 1994.

5. J.W. Sterbentz, "Low-Enriched Fuel Design Concept for the Prismatic Very High Temperature Reactor Core," Proceeding of ICAPP 2007, Paper 7098, Nice, France, May 13-18, 2007.

6. L. R. GREENWOOD and R. K. SMITHER, "SPECTER: Neutron Damage Calculations for Materials Irradiations,” ANL/FPP/TM-197, Argonne National laboratory, 1985. 